Cas Weykamp*, Sandra Secchiero, Mario Plebani, Marc Thelen, Christa Cobbaert, Annette Thomas, Nuthar Jassam, Julian H. Barth, Carmen Perich, Carmen Ricós and Ana Paula Faria

\title{
Analytical performance of 17 general chemistry analytes across countries and across manufacturers in the INPUtS project of EQA organizers in Italy, the Netherlands, Portugal, United Kingdom and Spain
}

DOI 10.1515/cclm-2016-0220

Received March 16, 2016; accepted June 24, 2016; previously published online July 22, 2016

\section{Abstract}

Background: Optimum patient care in relation to laboratory medicine is achieved when results of laboratory tests are equivalent, irrespective of the analytical platform used or the country where the laboratory is located. Standardization and harmonization minimize differences and the success of efforts to achieve this can be monitored with international category 1 external quality assessment (EQA) programs.

\footnotetext{
*Corresponding author: Cas Weykamp, SKML and Department of Clinical Chemistry, Queen Beatrix Hospital, Beatrixpark 1, 7101 BN Winterswijk, The Netherlands, Phone: +31543544774, Fax:+31543 524265, E-mail: c.w.weykamp@skbwinterswijk.nl Sandra Secchiero and Mario Plebani: Biomedical Research Center, Department of Laboratory Medicine, University Hospital of Padova, Padova, Italy. http://orcid.org/0000-0002-0270-1711 (M. Plebani) Marc Thelen: Dutch Foundation for Quality Assessment in Medical Laboratories (SKML), Nijmegen, The Netherlands, and Amphia Hospital, Department of Clinical Chemistry and Haematology, Breda, The Netherlands

Christa Cobbaert: SKML and Department of Clinical Chemistry, Leiden University Medical Center, Leiden, The Netherlands Annette Thomas: WEQAS, Cardiff and Vale University Health Board, Cardiff, UK

Nuthar Jassam: Department of Clinical Biochemistry, Harrogate District Foundation Trust, Harrogate, UK

Julian H. Barth: Department of Clinical Biochemistry, Leeds Teaching Hospitals NHS Trust, Leeds, UK

Carmen Perich: Quality Coordinator of Clinical Laboratory, Hospital Vall d'Hebron, Spain

Carmen Ricós: Spanish Society of Clinical Chemistry and Molecular Pathology (SEQC), Analytical Quality Commission, Spain Ana Paula Faria: National Health Institute Doutor Ricardo Jorge, Department of Epidemiology, Unity of External Quality Assessment, Lisbon, Portugal
}

Methods: An EQA project with commutable samples, targeted with reference measurement procedures (RMPs) was organized by EQA institutes in Italy, the Netherlands, Portugal, UK, and Spain. Results of 17 general chemistry analytes were evaluated across countries and across manufacturers according to performance specifications derived from biological variation (BV).

Results: For K, uric acid, glucose, cholesterol and highdensity density (HDL) cholesterol, the minimum performance specification was met in all countries and by all manufacturers. For $\mathrm{Na}, \mathrm{Cl}$, and $\mathrm{Ca}$, the minimum performance specifications were met by none of the countries and manufacturers. For enzymes, the situation was complicated, as standardization of results of enzymes toward RMPs was still not achieved in $20 \%$ of the laboratories and questionable in the remaining $80 \%$.

Conclusions: The overall performance of the measurement of 17 general chemistry analytes in European medical laboratories met the minimum performance specifications. In this general picture, there were no significant differences per country and no significant differences per manufacturer. There were major differences between the analytes. There were six analytes for which the minimum quality specifications were not met and manufacturers should improve their performance for these analytes. Standardization of results of enzymes requires ongoing efforts.

Keywords: commutability; external quality assessment; general chemistry; reference measurement procedures; total terror.

\section{Introduction}

Results between different laboratories should be equivalent, within clinically meaningful limits, and irrespective of analytical platforms used, or country in which 
the laboratory is located [1, 2]. This warrants the basis for uniform clinical decisions for the diagnosis and monitoring of patients, and ultimately enables optimum patient care from perspective of the medical laboratory. Absence of confusion on reference intervals and decision limits is appreciated by clinicians and strengthens the professional position of laboratory medicine [3]. Standardization and harmonization efforts minimize differences between laboratories and are the core issues of the International Federation of Clinical Chemistry and Laboratory Medicine (IFCC) and the American Association of Clinical Chemistry (AACC) [4, 5]. External quality assessment (EQA)/proficiency test (PT) organizers play an important role in monitoring the performance of individual laboratories, but also in supplying information on the progress of standardization/harmonization efforts [6-9]. In a recent review, EQA/PT schemes are categorized on basis of three characteristics: (a) commutability of the samples, (b) value assignment of targets (with a RMP or not), and (c) inclusion of replicate samples (yes or no) [10]. Optimum information is provided with category-1 programs with commutable replicate samples having values assigned with RMPs. This paper describes the results of such a program organized as a joint project by the national EQA organizers in Italy, the Netherlands, Portugal, UK, and Spain ("INPUtS" project; INPUtS derived from the initials in capitals of the five countries and $t$ to make a readable word and to express that all countries had "input" in this project) and is the extension of a previous pilot [11]. Performances of the laboratories are evaluated, both across countries and across analytical platforms of major manufacturers and interpreted according to specifications derived from biological variation (BV) [12]. The study therefore attempts to address the following questions: "Was there a difference in performance between countries $\mathrm{X}$ and $\mathrm{Y}$ ?", "Was there a difference in performance between the analytical platforms of manufacturers A and B?", and also "Was it feasible to share commutable samples by five national EQA organizers?”

\section{Materials and methods}

\section{Samples}

Each laboratory received a set of six commutable frozen human serum samples, regularly used in the national EQA program and manufactured by the Stichting Kwaliteitsbewaking Medische Laboratoria (SKML; Dutch EQA organization). Samples were shipped on dry ice and stored by the laboratories below $-70^{\circ} \mathrm{C}$ (or, when assayed within 2 weeks, at $-20^{\circ} \mathrm{C}$ ). Samples were thawed at room temperature and analyzed within $8 \mathrm{~h}$ after thawing. All target values were assigned with reference measurement procedures (RMP). Preparation, commutability and stability of the samples have been demonstrated and described in previous publications $[11,13]$. Table 1 shows the analytes included and their concentration range.

Table 1: Analytes, sample characteristics, biological variation, and total allowable error.

\begin{tabular}{|c|c|c|c|c|c|c|c|}
\hline \multirow[t]{2}{*}{ Analyte } & \multicolumn{2}{|c|}{ Concentration } & \multicolumn{2}{|c|}{$\begin{array}{r}\text { Biological } \\
\text { variation, \% }\end{array}$} & \multicolumn{3}{|c|}{ Total allowable error, \% } \\
\hline & Range & Units & CVI & CVG & Optimum & Desirable & Minimum \\
\hline $\mathrm{K}$ & $4.1-7.2$ & $\mathrm{mmol} / \mathrm{L}$ & 4.6 & 5.6 & 2.8 & 5.6 & 8.4 \\
\hline $\mathrm{Na}$ & $128-163$ & $\mathrm{mmol} / \mathrm{L}$ & 0.6 & 0.7 & 0.4 & 0.7 & 1.1 \\
\hline $\mathrm{Cl}$ & $88-112$ & $\mathrm{mmol} / \mathrm{L}$ & 1.2 & 1.5 & 0.7 & 1.5 & 2.2 \\
\hline $\mathrm{Ca}$ & $2.02-2.84$ & $\mathrm{mmol} / \mathrm{L}$ & 2.1 & 2.5 & 1.3 & 2.6 & 3.8 \\
\hline $\mathrm{Mg}$ & $0.8-1.7$ & $\mathrm{mmol} / \mathrm{L}$ & 3.6 & 6.4 & 2.4 & 4.8 & 7.2 \\
\hline Uric acid & $0.26-0.50$ & $\mathrm{mmol} / \mathrm{L}$ & 8.6 & 17.5 & 5.9 & 11.8 & 17.7 \\
\hline Glucose & $6.6-23.4$ & $\mathrm{mmol} / \mathrm{L}$ & 5.6 & 7.5 & 3.5 & 7.0 & 10.5 \\
\hline Total protein & $55-78$ & $\mathrm{~g} / \mathrm{L}$ & 2.8 & 4.7 & 1.8 & 3.7 & 5.6 \\
\hline Cholesterol & $4.1-6.0$ & $\mathrm{mmol} / \mathrm{L}$ & 6.0 & 15.3 & 4.5 & 9.0 & 13.5 \\
\hline HDL-cholesterol & $1.1-1.2$ & $\mathrm{mmol} / \mathrm{L}$ & 7.3 & 21.2 & 5.8 & 11.6 & 17.4 \\
\hline Amylase & $89-240$ & $\mathrm{U} / \mathrm{L}^{\mathrm{a}}$ & 8.7 & 28.3 & 7.3 & 14.6 & 21.9 \\
\hline ASAT & $47-131$ & $\mathrm{U} / \mathrm{L}^{\mathrm{a}}$ & 12.3 & 23.1 & 8.4 & 16.7 & 25.0 \\
\hline ALAT & $56-147$ & $\mathrm{U} / \mathrm{L}^{\mathrm{a}}$ & 19.4 & 41.6 & 13.8 & 27.5 & 41.2 \\
\hline CK & $146-388$ & $\mathrm{U} / \mathrm{L}^{\mathrm{a}}$ & 22.8 & 40.0 & 15.2 & 30.3 & 45.5 \\
\hline GGT & $44-140$ & $\mathrm{U} / \mathrm{L}^{\mathrm{a}}$ & 13.4 & 42.1 & 11.0 & 22.1 & 33.2 \\
\hline AP & $119-304$ & $\mathrm{U} / \mathrm{L}^{\mathrm{a}}$ & 6.4 & 26.1 & 6.0 & 12.0 & 18.0 \\
\hline LD & $226-901$ & $\mathrm{U} / \mathrm{L}^{\mathrm{a}}$ & 8.6 & 14.7 & 5.7 & 11.4 & 17.1 \\
\hline
\end{tabular}

${ }^{a}$ Measured with the respective IFCC reference measurement procedures. CVI, within-subject variation; CVG, between-subject variation. 


\section{Participants}

Table 2 shows the number of participating laboratories specified per country and per manufacturer. The laboratories of Italy, Spain, Portugal, and UK were randomly selected by the respective EQA organizers but with the criterion to achieve a number of 20-30 per country and to cover the common analytical platforms; samples were analyzed in addition to the respective regular EQA programs. In the Netherlands, the samples were part of the regular EQA program and thus analyzed by all laboratories. The analytical platforms of the manufacturers with comparable technology were considered as a group, leading to one group for Roche (all Cobas instruments) and Abbott (all Architect models), and to two groups for Beckman-Coulter (UniCel-DxC and Olympus AU instruments) and Siemens (Dimension and Advia instruments).

\section{Calculations at analyte level}

For each sample and each group (group=all laboratories, all laboratories of a country, or all laboratories using the platforms of the same manufacturer), the bias of the mean of that group (bias=mean of the group - target established with the RMP), and the betweenlaboratory coefficient of variation (CV) were calculated. From these, the mean bias $(\mathrm{B})$ and mean between-laboratory $\mathrm{CV}\left(\mathrm{CV}_{\mathrm{m}}\right)$ of the six samples were calculated and used to calculate the total error (TE) of the group according to $\mathrm{TE}=|\mathrm{B}|+2 \mathrm{CV}_{\mathrm{m}}[14]$. TEs were compared with the total allowable error (TAE) calculated on basis of the BV taken from the BV specifications database by Ricós et al. [15] and classified as meeting the optimum, desirable, or minimum specification (or as not meeting any of the three criteria). BVs and TAEs are summarized in Table 1. In addition to the results of the individual countries, these calculations were also made for the Italian, Spanish, Portuguese, and UK laboratories as one group. The overall mean is the mean of the Italian, Spanish, Portuguese, and UK laboratories. Results of the Dutch laboratories were excluded from the calculation of the overall mean (to prevent unbalanced data due to the large number of laboratories in comparison to the other countries). For the figures, the model of the IFCC Task Force on $\mathrm{HbA}_{1 c}$ was used [16].

\section{Calculations at aggregated level}

To summarize the performance of all 17 analytes in one number, the median TE/TAE ratio was calculated: TE/TAE ratio $=\{\Sigma(\mathrm{TE} /$

Table 2: Number of participants per country and per manufacturer.

\begin{tabular}{lrrrrrr}
\hline Manufacturer & ES & IT & PT & UK & $\begin{array}{r}\text { Total ES-IT- } \\
\text { PT-UK }\end{array}$ & NL \\
\hline Abbott Architect & 2 & 6 & 3 & 4 & 15 & 17 \\
Beckman Coulter Olympus & 5 & 6 & 3 & 5 & 19 & 8 \\
Beckman Coulter UniCel DxC & 1 & 7 & 0 & 0 & 8 & 32 \\
Roche Cobas & 7 & 7 & 8 & 8 & 30 & 139 \\
Siemens Advia & 2 & 0 & 3 & 3 & 8 & 5 \\
Siemens Dimension & 2 & 6 & 2 & 0 & 10 & 11 \\
Total & 19 & 32 & 19 & 20 & 90 & 212 \\
\hline
\end{tabular}

$\left.\left.\mathrm{TAE}_{\text {minimum }}\right)\right\} / 17$ in which $\mathrm{TAE}_{\text {minimum }}$ is the TAE for the respective 17 analytes at the minimum performance level.

\section{Results}

\section{Analyte level}

TE's for country and manufacturer groups are summarized in Table 3. The underlying bias (B) and betweenlaboratory CV $\left(\mathrm{CV}_{\mathrm{m}}\right)$ are listed in Supplemental Tables 1 (for countries) and 2 (for manufacturers). Colors indicate whether the TEs met one of the TAE specifications for optimum (yellow), desirable (gray), minimum performance (amber), or not (white). Yellow, gray and amber can also be read as gold, silver, and bronze performance. It can be seen that for sodium ( $\mathrm{Na}$ ), none of the countries and manufacturers even met the minimum specification (thus all white). For glucose, all countries and manufacturers met one of the specifications: gold (one manufacturer), silver (two countries; three manufacturers), and bronze (four countries; two manufacturers). Table 3 shows all numerical TEs; however, when none of the specifications are met, the degree and source (bias and imprecision component) of TE cannot be readily identified. These issues are addressed in Figure $1 \mathrm{~A}$ and B, with results for total protein enlarged as an example. The TAE for minimum performance of total protein is $5.6 \%$ (see Table 1). According to $\mathrm{TE}=\mathrm{B}+2 \mathrm{CV}_{\mathrm{m}}$, a TE of $5.6 \%$ can be achieved either with a $\mathrm{B}$ of $5.6 \%$ and a $\mathrm{CV}_{\mathrm{m}}$ of $0.0 \%$ or (the other extreme) with a B of $0.0 \%$ and $\mathrm{C} \mathrm{CV}_{\mathrm{m}}$ of $2.8 \%$. These extremes are plotted in the figure: a B of $5.6 \%$ on the $y$-axis and $\mathrm{CV}_{\mathrm{m}}$ of $2.8 \%$ on the $\mathrm{x}$-axis. Similarly, the extremes for desirable and optimum performance were calculated (B's of 3.7 and $1.8 \% ; \mathrm{CV}_{\mathrm{m}}$ 's of 1.8 and $0.9 \%$ ). The extremes on both axes are the limits of triangles for a golden optimum, a silver desirable, and a bronze minimum performance. The TEs of the countries (left side) and manufacturers (right side) are visualized by plotting the respective B's and $\mathrm{CV}_{\mathrm{m}}$ 's (taken from Supplemental Tables 1 and 2). For total protein, it can be seen that of the countries, only UK (U; red) met the minimum specification. The manufacturer graph shows that Siemens Dimension (D; brown), Siemens Vista (S; purple) and Beckman-Coulter Olympus $\mathrm{AU}(\mathrm{O}$; green) were within the minimum specifications. Abbott (A; red) and Roche (R; yellow) were moderately outside, and Beckman-Coulter UniCel DxC (B; blue) was far outside the specifications. The performance of all the other analytes are visualized with respect to country and manufacturer. The enzymes in Table 3 and Figure 1 
Table 3: Total error (\%) and TE/TAE ratio per country and per manufacturer.

\begin{tabular}{|c|c|c|c|c|c|c|c|c|c|c|c|c|}
\hline \multirow[t]{2}{*}{ Analyte } & \multicolumn{6}{|c|}{ Countries } & \multicolumn{6}{|c|}{ Manufacturers } \\
\hline & ES & IT & PT & UK & All & NL & Abb & Oly & $\mathrm{Bec}$ & Roc & SAd & SDi \\
\hline K & 5.4 & 5.8 & 7.6 & 5.1 & 6.1 & 4.7 & 7.8 & 6.3 & 3.3 & 4.1 & 4.4 & 7.1 \\
\hline $\mathrm{Na}$ & 4.1 & 3.3 & 4.9 & 2.8 & 3.9 & 3.2 & 4.0 & 4.0 & 3.1 & 3.2 & 1.9 & 4.2 \\
\hline $\mathrm{Cl}$ & 5.1 & 4.3 & 5.0 & 5.1 & 5.1 & 4.0 & 3.9 & 4.7 & 3.4 & 4.4 & 5.1 & 6.1 \\
\hline $\mathrm{Ca}$ & 7.1 & 6.3 & 7.3 & 5.4 & 6.3 & 5.2 & 6.4 & 7.0 & 6.5 & 4.5 & 7.2 & 8.5 \\
\hline $\mathrm{Mg}$ & 9.7 & 12 & 12 & 8.2 & 11 & 7.2 & 9.9 & 8.5 & 26 & 7.1 & 10 & 13 \\
\hline Uric acid & 14 & 14 & 11 & 7.4 & 12 & 10 & 6.8 & 5.5 & 4.4 & 9.2 & 5.5 & 17 \\
\hline Glucose & 7.7 & 6.8 & 8.3 & 8.0 & 7.5 & 6.7 & 7.1 & 8.7 & 2.9 & 6.8 & 4.9 & 6.3 \\
\hline Total protein & 7.2 & 7.9 & 8.5 & 5.0 & 7.3 & 6.4 & 6.6 & 5.2 & 11 & 8.0 & 4.8 & 4.5 \\
\hline Cholesterol & 10 & 7.1 & 7.2 & 7.1 & 7.9 & 7.5 & 5.9 & 10 & 5.0 & 4.9 & 5.3 & 7.5 \\
\hline HDL-Chol & 12 & 13 & 14 & 13 & 13 & 12 & 19 & 10 & 12 & 9.7 & 14 & 13 \\
\hline Amylase $^{a}$ & 13 & 19 & 24 & 23 & 21 & 9.3 & 23 & 32 & 11 & 14 & 14 & - \\
\hline $\mathrm{ASAT}^{\mathrm{a}}$ & 16 & 7.0 & 24 & 29 & 27 & 10 & 33 & 18 & 32 & 28 & 22 & 18 \\
\hline $\mathrm{ALAT}^{\mathrm{a}}$ & 29 & 26 & 38 & 29 & 31 & 8.1 & 29 & 20 & 39 & 32 & 25 & 25 \\
\hline $\mathrm{CK}^{\mathrm{a}}$ & 18 & 16 & 21 & 9.2 & 16 & 11 & 9.3 & 19 & - & 16 & 13 & 11 \\
\hline $\mathrm{GGT}^{\mathrm{a}}$ & 22 & 24 & 21 & 11 & 21 & 10 & 16 & 11 & - & 22 & 13 & 22 \\
\hline $\mathrm{AP}^{\mathrm{a}}$ & 25 & 31 & 27 & 20 & 27 & 16 & 31 & 15 & 33 & 16 & 17 & 18 \\
\hline $\mathrm{LD}^{\mathrm{a}}$ & 11 & 14 & 17 & 11 & 16 & 8.4 & 15 & 27 & 11 & 10 & 11 & 4.2 \\
\hline TE/TAE ratio & 0.7 & 0.7 & 0.9 & 0.8 & 1.0 & 0.6 & 1.1 & 0.8 & 0.7 & 0.7 & 0.6 & 0.7 \\
\hline
\end{tabular}

${ }^{a}$ For enzymes, the data of IFCC traceable laboratories. Amber (bronze), meets minimum criterion; Gray (silver), meets desirable criterion; Yellow (gold), meets optimum criterion; Abb, Abbott Architect; Oly, Beckman-Coulter Olympus; Bec, Beckman-Coulter UniCel DxC; Roc, Roche; SAd, Siemens Advia; SDi, Siemens Dimension; TE/TAE ratio, median ratio (TE/TAE minimum) of all analytes.

are from laboratories using methods claimed to be traceable to the respective IFCC RMPs only. The percentages of (excluded) laboratories not reporting in units traceable to the IFCC RMPs are provided in Table 4.

\section{Aggregated level}

Results can also be reviewed at a higher aggregation level. Especially when a new analytical platform is considered, it is convenient to describe the performance as one number, rather than numbers for each of the analytes. The performance of a platform is expressed as the median TE/TAE ratio of the 17 analytes. When the observed TE of an analyte and TAE at the minimum performance level of that analyte are equal, the TE/TAE ratio is 1.0. At the ratio of 1.0, that analyte just meets the minimum performance specification. The higher the TE/TAE ratio, the worse the performance. The median TE/TAE ratio of the 17 analytes is an overall estimate of performance. Median TE/TAE ratios are shown in Table 3 (bottom line; detailed calculations in Supplemental Table 3) and are visualized in Figure 2. For comparison, the ratios of three analytes ( $\mathrm{Na}, \mathrm{Ca}$, and $\mathrm{CK}$ ) are also included in Figure 2. It can be seen that there is little difference in performance between countries or between manufacturers. For $\mathrm{Na}$ and $\mathrm{Ca}$, the ratio is high, and for $\mathrm{CK}$, the ratio is low in all countries and for all manufacturers. This also applies for the median ratio with all values within the minimum or just within the desirable performance specifications. Figure 2 also shows the overall ratio (irrespective of country and manufacturer) as an estimate of the analytical performance of the respective analytes: the minimum, desirable, and optimum performance specifications are met by 8,2 , and 1 analytes, respectively. Six analytes did not meet any of these specifications.

\section{Discussion}

In this study, we aimed to estimate the analytical performance of 17 general chemistry analytes in European medical laboratories. The design of the study reflected this aim: (a) commutable samples with target values assigned with RMPs, (b) input from five countries, (c) inclusion of analytical platforms from the major manufacturers, (d) sound data derived from the mean of six samples, and (e) clear performance specifications derived from BV data. This approach is in line with the outcome of the 2014 European Federation of Clinical Chemistry and 

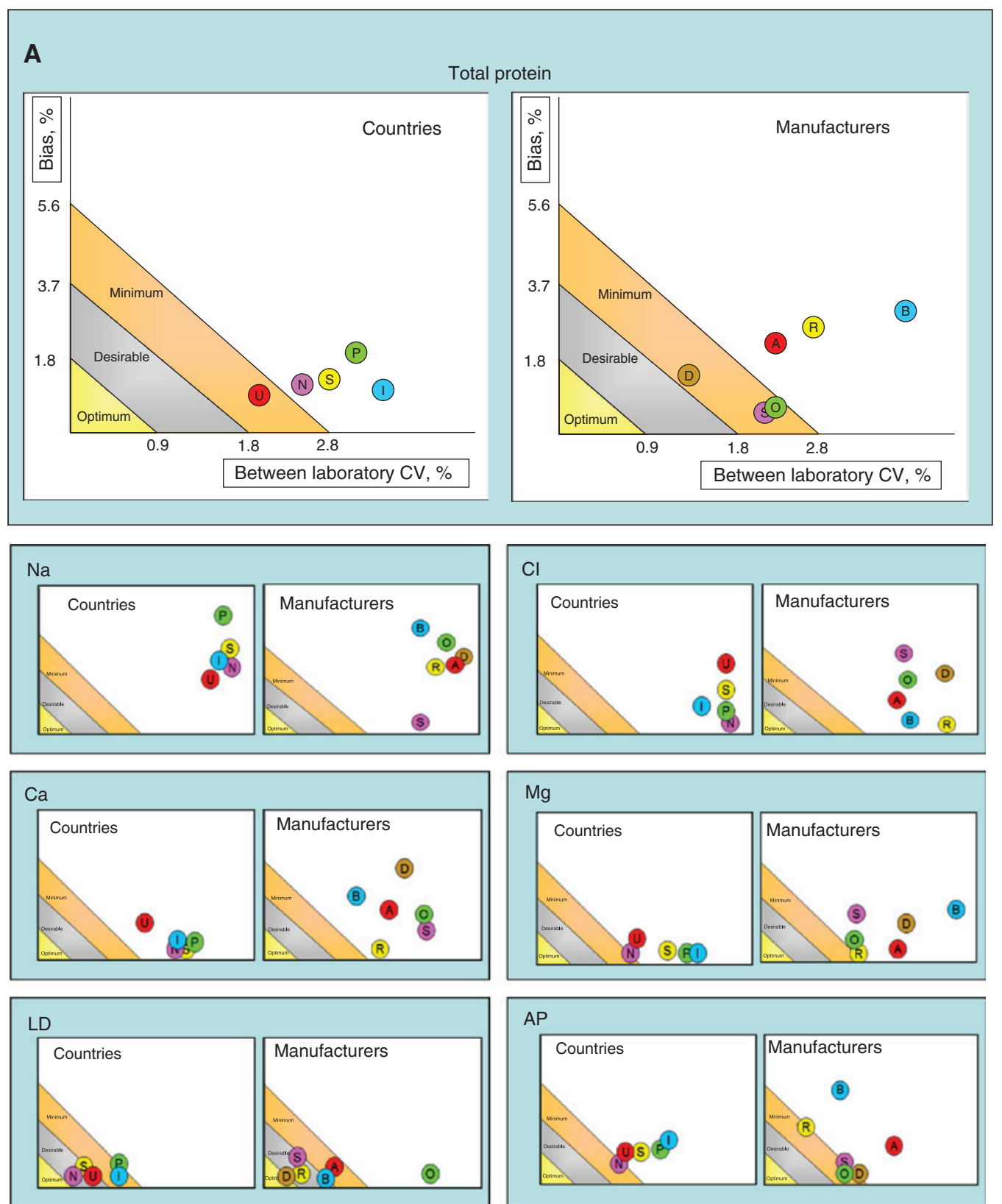

Countries
(1) Italy
(N) Netherlands
(P) Portugal
(C) United Kingdom
(t) $\mathrm{t}$
(S) Spain

Manufacturers
(A) Abbott
(B) Beckman Coulter DxC
(O) Beckman Coulter Olympus
(B) Roche
(S) Siemens Advia
(D) Siemens Dimension

Figure 1: Performance per country and per manufacturer.

For each of the analytes, bias (y-axis) and between laboratory CV (x-axis) are plotted for countries on the left (I, blue=Italy; N, purple=the Netherlands; P, green=Portugal; U, red=United Kingdom; S, yellow=Spain) and manufacturers on the right (A, red=Abbott Architect; B, blue=Beckman Coulter UniCel DxC; O, green=Beckman Coulter Olympus AU; R, yellow=Roche Cobas; S, purple=Siemens Advia; D, brown=Siemens Dimension). Specifications for minimum, desirable, and optimum performance are indicated by the amber, gray, and yellow triangles, respectively. 

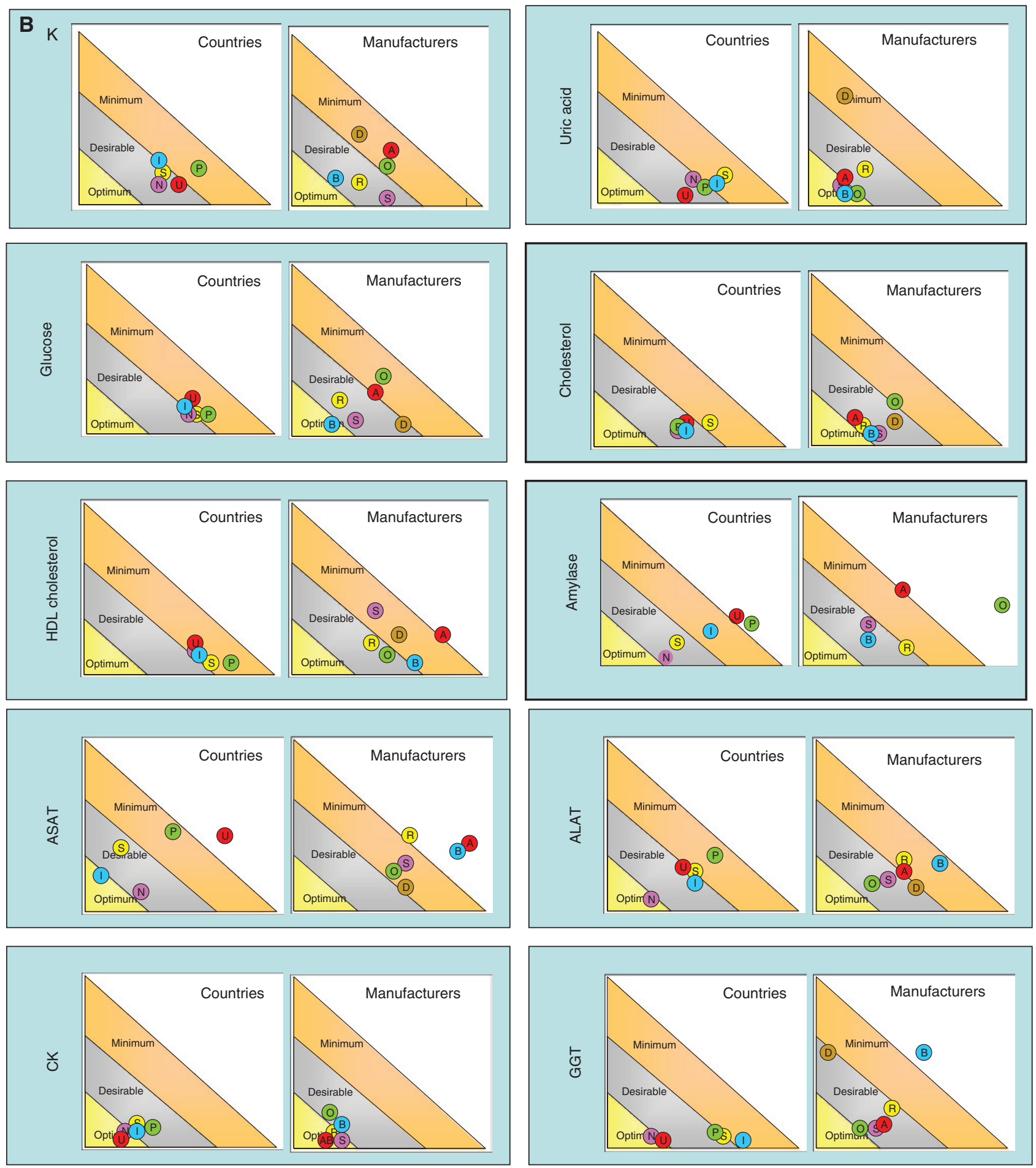

Figure 1 (continued)

Laboratory Medicine (EFLM) strategic conference on analytical performance specifications in laboratory medicine [17]. Results were not evaluated at the level of individual laboratories. This paper focuses on aggregated data: for each country and each manufacturer.

\section{Performance at analyte level}

Table 3 and Figure 1 clearly demonstrate that the performance of the individual analytes $\mathrm{K}$, uric acid, glucose, and cholesterol performed satisfactory: the minimum 
Table 4: Percentage laboratories not reporting enzyme results in units traceable to the IFCC RMP.

\begin{tabular}{|c|c|c|c|c|c|c|c|c|c|c|c|c|}
\hline \multirow[t]{2}{*}{ Enzyme } & \multicolumn{5}{|c|}{ Countries } & & & & & \multicolumn{2}{|c|}{ Manufacturers } & \multirow[t]{2}{*}{ Mean $^{\circ}$} \\
\hline & ES & IT & PT & UK & NL & Abb & Oly & Bec & Roc & Adv & Dim & \\
\hline GGT & 16 & 22 & 21 & 2 & 4 & 20 & 5 & 88 & 7 & 0 & 11 & 16 \\
\hline CK & 11 & 41 & 11 & 10 & 4 & 20 & 11 & 88 & 0 & 12 & 60 & 20 \\
\hline ALAT & 32 & 0 & 16 & 15 & 3 & 27 & 11 & 0 & 17 & 0 & 10 & 14 \\
\hline ASAT & 37 & 0 & 16 & 11 & 2 & 27 & 11 & 0 & 14 & 0 & 20 & 14 \\
\hline Amylase & 31 & 41 & 22 & 30 & 14 & 73 & 25 & 0 & 10 & 0 & 88 & 29 \\
\hline LD & 24 & 34 & 26 & 37 & 4 & 0 & 44 & 38 & 43 & 38 & 0 & 31 \\
\hline $\mathrm{AP}$ & 28 & 3 & 16 & 10 & 4 & 20 & 21 & 0 & 0 & 25 & 30 & 14 \\
\hline Mean & 26 & 20 & 18 & 16 & 5 & 27 & 18 & 31 & 13 & 11 & 30 & 20 \\
\hline
\end{tabular}

${ }^{a}$ NL not included. ES, Spain; IT, Italy; PT, Portugal; UK, United Kingdom; NL, Netherlands; Abb, Abbott Architect; Oly, Beckman-Coulter Olympus; Bec, Beckman-Coulter UniCel DxC; Roc, Roche Cobas; Adv, Siemens Advia; Dim, Siemens Dimension.
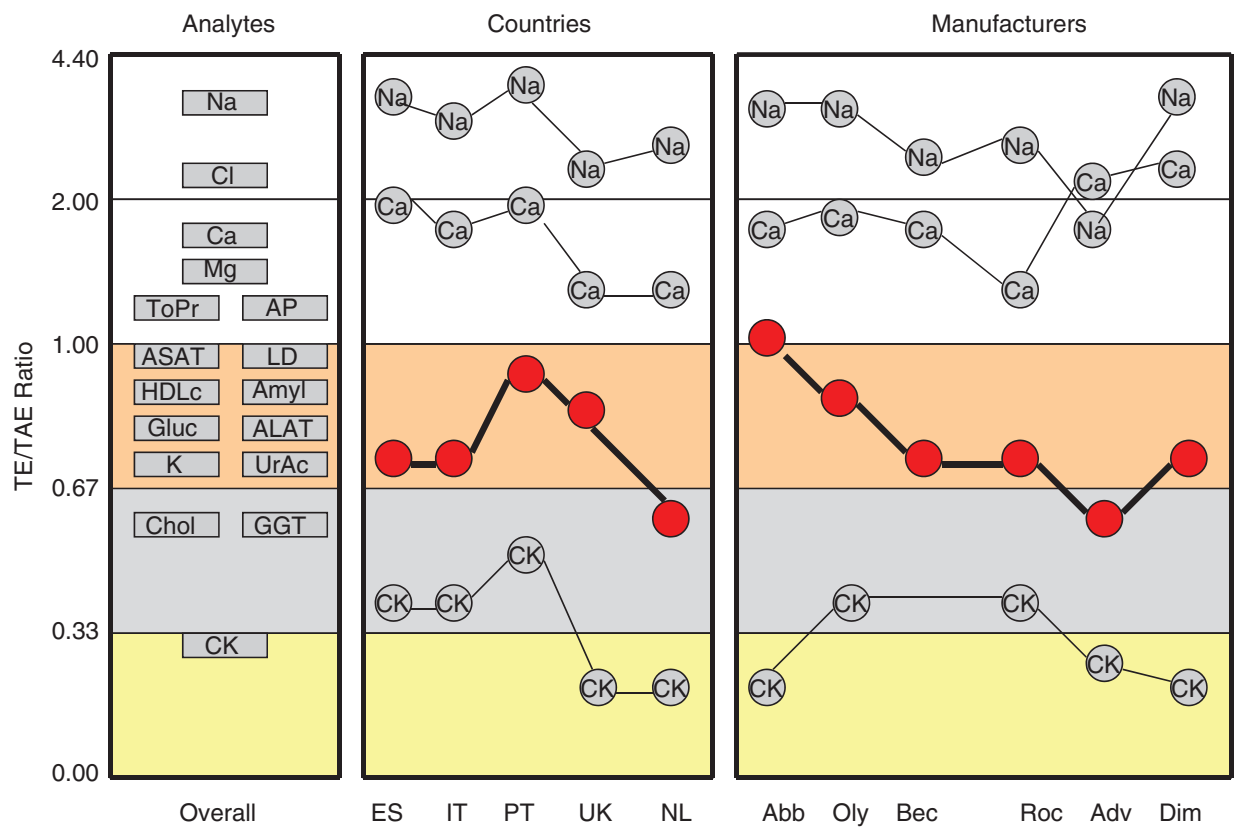

Figure 2: Overall, country and manufacturer specific TE/TAE ratios.

The TAE/TE ratio is plotted on the y-axis with indication of ratios corresponding to specifications for optimum (yellow), desirable (gray), and minimum (amber) performance. Countries (ES, Spain; IT, Italy; PT, Portugal; UK, United Kingdom; NL, Netherlands) and manufacturers (Abb, Abbott Architect; Oly, Beckman-Coulter Olympus; Bec, Beckman-Coulter UniCel DxC; Roc, Roche Cobas; Adv, Siemens Advia; Dim, Siemens Dimension) are plotted on the $\mathrm{x}$-axis. The median ratio of 17 analytes (red dots) and analyte specific ratios of three analytes (gray; $\mathrm{Na}$, $\mathrm{Ca}$, CK) are plotted per country (middle part) and per manufacturer (right part). Gray squares (left part) represent overall ratios for the respective analytes (ToPr, total protein; AP, alkaline phosphatase; ASAT, aspartate aminotransferase; HDLc, high-density lipoprotein cholesterol; Amyl, amylase; Gluc, glucose; ALAT, alanine aminotransferase; UrAc, uric acid; Chol, cholesterol).

performance specification is met in all countries and by all manufacturers. The opposite applies to $\mathrm{Na}, \mathrm{Cl}$, and Ca: in that none of the countries or manufacturers met the minimum specification. For $\mathrm{Mg}$, high-density lipoprotein (HDL) cholesterol, and total protein the performance can be considered borderline: in that some countries and manufacturers met the specification whilst others did not. For the enzymes the situation was more complicated in that despite efforts from the IFCC, approximately $20 \%$ of laboratories used methods that were not traceable to the IFCC RMPs. Percentages differed per enzyme, per country, and per manufacturer (Table 4). Non-traceable results were excluded from the calculations for Table 3 and Figure 1. The reliability of the remaining results for which IFCC-traceability was claimed is also questionable. Classification was different 
per country: traceability was either assumed by the laboratories, or assigned by the EQA organizers based on the results (a number of EQA organizers expressed concern that that the laboratories had insufficient awareness of traceability). This is also confirmed by the fact that the between-laboratory CV in Spain, Italy, Portugal and UK is approximately double that of the Netherlands where strict standardization was implemented as part of a concerted awareness and implementation initiative from the association of clinical chemists, manufacturers, and the EQA organizer [3, 13].

\section{Performance at aggregated level}

The horizontal distribution of the red dots in Figure 2 demonstrates that the overall performance in the countries and of respective manufacturers is not very different. A similar horizontal distribution is seen for the gray dots of $\mathrm{Na}, \mathrm{Ca}$, and $\mathrm{CK}$ (and all other analytes - $\mathrm{Na}$, $\mathrm{Ca}$ and $\mathrm{CK}$ are just an example; see Supplemental Table 3). The TE/TAE ratios for $\mathrm{Na}$ (3.5) and $\mathrm{Ca}$ (1.7) are much higher than 1.0, indicating that the minimum performance specification for these analytes was not achievable if BV data are used to define performance specifications. This applied to all countries and to all manufacturers. CK is an example of the other extreme where low ratios were observed within the desirable or even the optimum performance specifications for all countries by all manufacturers. The study suggests that the analytical performance of general chemistry analysers is not related to differences in skills in the respective countries and is also not related to analytical platform of a specific manufacturer. However, the performance and therefore the state of the art for each analyte is very different.

\section{Comparison with similar EQA concepts}

There are only a few EQA schemes using commutable samples, most of them related to the group of Thienpont et al. [6-9]. It is worth considering the differences between our two approaches in terms of the findings of our schemes and the use of slightly different samples.

For many analytes, our findings were comparable, e.g. glucose and cholesterol met, quality criteria whereas HDL cholesterol (Abbott) did not [8], neither did calcium and total protein meet the criteria [6]. We found that alkaline phosphatase (AP), alanine aminotransferase (ALAT), aspartate aminotransferase (ASAT), and lactate dehydrogenase (LD) were not traceable to the respective IFCC
RMPs. We did not subdivide the transaminases based on the way of pyridoxalphosphate activation as previous investigations showed that traceability may not be substrate dependent [3].

However, some of our findings differed from the Thienpont group. They observed a 3.6\% negative bias for chloride with the Roche Cobas system [7]. We believe that this highlighted a temporary effect on the Roche systems. We evidence this on the longitudinal data from the Dutch EQA program which has used commutable materials since 2005. Data from the years 2012-2015 show that the Cobas had a bias of $-0.4,-0.6,-2.9$, and $-0.4 \%$ (Roche Modular bias is $+1.0,+0.6,-1.1$, and $-0.3 \%$ ). The "dip" seen in 2014 was only temporary and has now disappeared. Our data and that of Thienpont's group may have been affected by this. It is possible that other contrasting findings, e.g. uric acid and $\mathrm{Mg}$ (Abbott) had a similar cause [6].

Although we and Thienpont's group have both used commutable frozen human sera, there are some differences. We used fresh frozen human sera pools, whereas Thienpont et al. used panels of 20 fresh frozen single donation human sera. We do not know whether this complicates any comparison. The advantage of single donation is that assay non-specificity can be more easily detected, but a single donation has a maximum volume of approximately $200 \mathrm{~mL}$ and a proportion of each sample has to be used for targeting, homogeneity, and stability testing. In contrast, large sample pools include the option to recruit large numbers of participating laboratories, reissue the same pool over long periods, and the ability to test over a broader range of analyte concentrations. Furthermore, the costs of value assignment with RMPs is relastively lower for pools than for small single donations.

In this paper, we have chosen to focus our evaluation on the performance of groups (either manufacturers or countries) and not on individual laboratories. Results allowed the individual laboratories to evaluate their own compliance to analytical performance specifications in line with the proposals of the EFLM conference on analytical quality [17], which is only possible with a category-1 EQA scheme.

\section{Conclusions}

Overall, the analytical performance of 11 of 17 general chemistry analytes measured in European medical laboratories met the minimum performance specifications. There were no significant differences between 
the countries or between manufacturers. There were however, major differences between the analytes. There are six analytes for which the minimum quality specifications are not met and manufacturers should strive to improve their performance for these analytes. Standardization of enzyme methods towards IFCC RMPs has not been fully achieved and requires ongoing efforts. The study demonstrated that it is feasible for national EQA organizers to share fresh frozen commutable human sera and that retrospective combination of their data reveals a pan-European picture of analytical quality.

Acknowledgments: The authors acknowledge Irene de Graaf for her work on the processing and re-processing of all results.

Author contributions: All the authors have accepted responsibility for the entire content of this submitted manuscript and approved submission.

Research funding: None declared.

Employment or leadership: None declared.

Honorarium: None declared.

Competing interests: The funding organization(s) played no role in the study design; in the collection, analysis, and interpretation of data; in the writing of the report; or in the decision to submit the report for publication.

\section{References}

1. Miller WG, Myers GL, Gantzer MI, Kahn SE, Schönbrunner ER, Thienpont LM, et al. Roadmap for harmonization of clinical laboratory measurement procedures. Clin Chem 2011;57:1108-17.

2. Plebani M. Harmonization in laboratory medicine: requests, samples, measurements and reports. Crit Rev Clin Lab Sci 2015;15:1-13.

3. Weykamp C, Franck P, Klein Gunnewiek J, de Jonge R, Kuypers A, van Loon D, et al. Harmonization of seven common enzyme results through EQA. Clin Chem Lab Med 2014;52:1549-55.

4. Available at: www.ifcc.org/ifcc-scientific-division/sdcommittees/c-tlm/. Accessed January 2016.

5. Available at: www.harmonization.net/about/Pages/default. html\#.Vs70eFceBIQ. Accessed January 2016.
6. Stepman CM, Tiikkainen U, Stöckl D, Vesper HW, Edwards SH, Laitinen $\mathrm{H}$, et al. Measurements for 8 common analytes in native sera identify inadequate standardization among 6 routine laboratory assays. Clin Chem 2014;60:855-63.

7. Goossens K, Van Uytfanghe K, Thienpont LM. Trueness and comparability assessment of widely used assays for 5 common enzymes and 3 electrolytes. Clin Chim Acta 2015;442:44-45.

8. Van Houcke SK, Rustad P, Stepman HC, Kristensen GB, Stöckl D, Roraas TH, et al. Calcium, magnesium, albumin, and total protein measurement in serum as assessed with 20 fresh-frozen single-donation sera. Clin Chem 2012;58:1597-9.

9. De Grande LA, Goossens K, Van Uytfanghe K, Stöckl D, Thienpont LM. The empower project - a new way of assessing and monitoring test comparability and stability. Clin Chem Lab Med 2015;53:1197-204.

10. Miller WG, Jones GR, Horowitz GL, Weykamp C. Proficiency testing/external quality assessment: current challenges and future directions. Clin Chem 2011;57:1670-80.

11. Jansen R, Jassam N, Thomas A, Perich C, Fernandez-Calle P, Faria $A$, et al. A category 1 EQA scheme for comparison of laboratory performance and method performance: an international pilot study in the framework of the Calibration 2000 project. Clin Chim Acta 2014;432:90-8.

12. Fraser CG, Hyltoft Petersen P, Libeer JC, Ricos C. Proposal for setting generally applicable quality goals solely based on biology. Ann Clin Biochem 1997;34:8-12.

13. Cobbaert C, Weykamp C, Franck P, de Jonge R, Kuypers A, Steigstra $\mathrm{H}$, et al. Systematic monitoring of standardization and harmonization status with commutable EQA-samples five year experience from the Netherlands. Clin Chim Acta 2012;414:234-40.

14. Westgard JO, Westgard SA. Total analytical error: from concept to application. www.aacc.org/publications/cln/articles/2013/ september/total-analytic-error. Accessed January 2016.

15. Minchinela J, Ricós C, Perich C, Fernández-Calle P, Álvarez V, Doménech MV, et al. Biological variation database and quality specifications for imprecision, bias and total error (desirable and minimum). The 2014 update. http://www.westgard.com/ biodatabase-2014-update.htm. Accessed January 2016.

16. Weykamp C, John G, Gillery P, English E, Ji L, Lenters-Westra E. Investigation of 2 models to set and evaluate quality targets for HbA1c: biological variation and sigma-metrics. Clin Chem 2015;61:752-59.

17. Panteghini M, Sandberg S. Defining analytical performance specifications 15 years after the Stockholm conference. Clin Chem Lab Med 2015;53:829-32.

Supplemental Material: The online version of this article (DOI: 10.1515/cclm-2016-0220) offers supplementary material, available to authorized users. 